\title{
Peculiar features of social infrastructure development for the purposes of enhancement of urban environment comfort
}

\author{
Alexandr Orlov $^{1, *}$ and Irina Chubarkina ${ }^{1}$ \\ ${ }^{1}$ Moscow State University of Civil Engineering, 129337, Yaroslavskoye shosse, 26, Moscow, Russia
}

\begin{abstract}
The article considers new models of strategic territorial planning combined with infrastructure development that contribute to a more compact urban development. The main methodological provisions of the Blue Ocean strategy are analyzed and presented in the form of the value approach. A city planning unit called "urban block" is used as a strategic solution in relation to this strategy and construction of a "compact city". Factor space is formed taking into account the value for the consumer within the framework of the value approach. A three-factor model is created to improve the efficiency of investment and construction project implementation. The efficiency of the construction project is assessed. The value approach can be used both for projects that presuppose only budgetary financing and projects that have a commercial component. The provisions set forth in the article can be used to solve problems concerning enhancement of the urban environment comfort and creation of a new infrastructure. In general, it will contribute to the modernization of capital construction funds and creation of new productive forces.
\end{abstract}

\section{Introduction}

Improvement of the quality of sustainable urban development is among the solutions to many problems that cities face today. Studies showed that urban planning systems changed a little in many countries of the world and often serve as a source of urban problems rather than a means of improvement of the environment and living conditions [1,2]. Considering this, it can be concluded that it is necessary to replace existing approaches to planning by those ones that will contribute to sustainable urban development.

Urban planning must be carried out taking into account the following factors:

- Environmental problems caused by climate change and excessive dependence on vehicles.

- Economic problems associated with the uncertainty of future economic development and the global financial crisis.

- Social and territorial problems caused by insufficient residential floor space available to the population [3].

\footnotetext{
*Corresponding author: alor333@gmail.com
} 
Studies also showed that recently new methods have been applied for city planning, which are distinguished by higher flexibility, strategic orientation and practicability. They include strategic territorial planning, planning of new and more rational territorial forms, such as compact cities and construction of microdistricts with smart infrastructure elements $[4,5]$.

Strategic territorial planning combined with infrastructure development contributes to a more compact urban development [6,7]. In this respect linking of strategic planning to major investment and construction projects taking into account infrastructure development assumes great importance. Infrastructure planning is the key element in such strategic plans.

So, the purpose of this research is to study a new method of urban planning as a positive process that facilitates better access to services and the growth of socio-economic opportunities, and determine its effectiveness.

\section{Methodical foundations}

The methodological base of the research is represented by generally accepted scientific methods that ensure comprehensiveness, consistency and reliability of research results, such as scientific analysis and synthesis, grouping, comparison and generalization, economic analysis, financial modeling of cash flows and methodological approaches to the Blue Ocean strategy.

Under current conditions strategic management is of a fairly high importance. Strategic management is the process of strategy formation, its implementation and monitoring of the compliance of results achieved with planned targets [8].

In this case the author proposes to apply the strategy of value innovation, the methodological foundations that are applied in the Blue Ocean strategy proposed by Kim Chan and Renee Mauborgne from the Institute of the Blue Ocean Strategy of INSEAD (European top business school) [9]. The strategy under consideration promotes an increase in the efficiency of investment activity of enterprises operating in the construction sector thanks to the long-term competitiveness on the real estate market. This strategy is aimed at encouraging the enterprise to break out of the Red (competitive) Ocean by creating a market niche, in which it is possible not to be afraid of competitors due to the creation of new and rapidly growing demand [10-14].

Value innovation is represented by the "value approach" (Figure 1), which represents a set of strategic solutions in investment and construction activities based on the reduction of costs for enterprises operating in the construction industry and an increase in the value for buyers of real estate.

So, the strategic choice for enterprises applying this value approach is to create new rules of best practice, for which the "value-cost" compromise is broken down and a new market niche free from competitors is created.

A new urban planning unit with the working name "urban block" can be applied as a strategic solution in respect to the value approach and construction of a "compact city" as exemplified by construction of microdistricts.

An urban block is represented by apartment houses with service facilities located at street level and a courtyard that consists of private, closed areas [15-17]. 


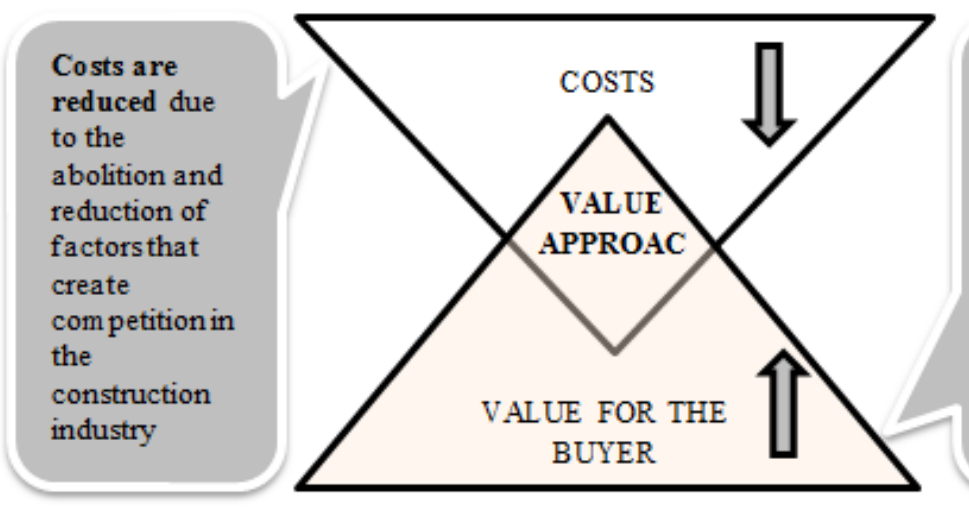

Value for the buyer increases due to the creation and developm ent of elem ents that the construction industry has never offered

Fig. 1. Methodological foundations of the value approach.

Private areas are allocated within an urban block and represent courtyards with trees and shrubs, with playgrounds for young children and recreation; private areas are free from transport (except special vehicles).

Public areas are allocated within a city block and include driveways, parking lots, garden squares, boulevards; it is planned to allocate mainly utilitarian public areas (with driveways, parking lots, public utility sites) and pedestrian green areas [18-20].

A city block in this case will consist of a set of urban blocks, public areas with driveways, parking lots, recreational areas, and a block green belt (Fig. 2).

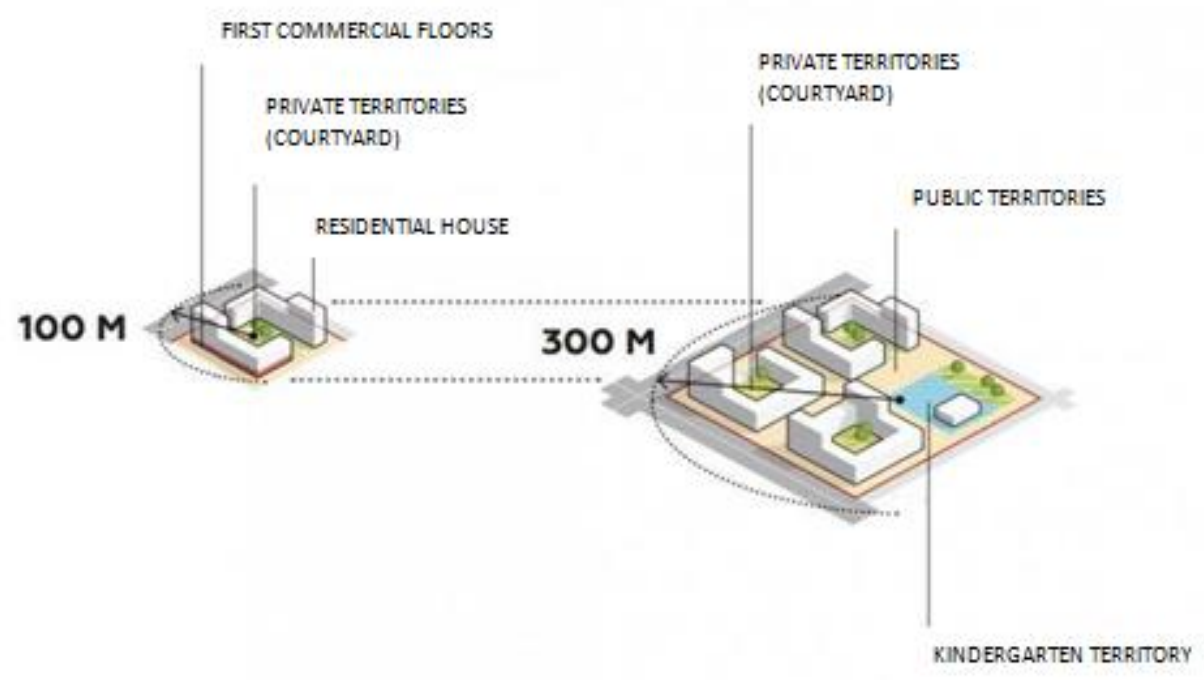

Fig. 2. Urban blocks and a city block.

A microdistrict will include city blocks, streets and driveways, functional purpose buildings, including schools, health and fitness centers, a microdistrict center, utility facilities, recreation common areas with trees and shrubs, kindergartens, day-to-day service facilities, detached garages (Fig. 3). 


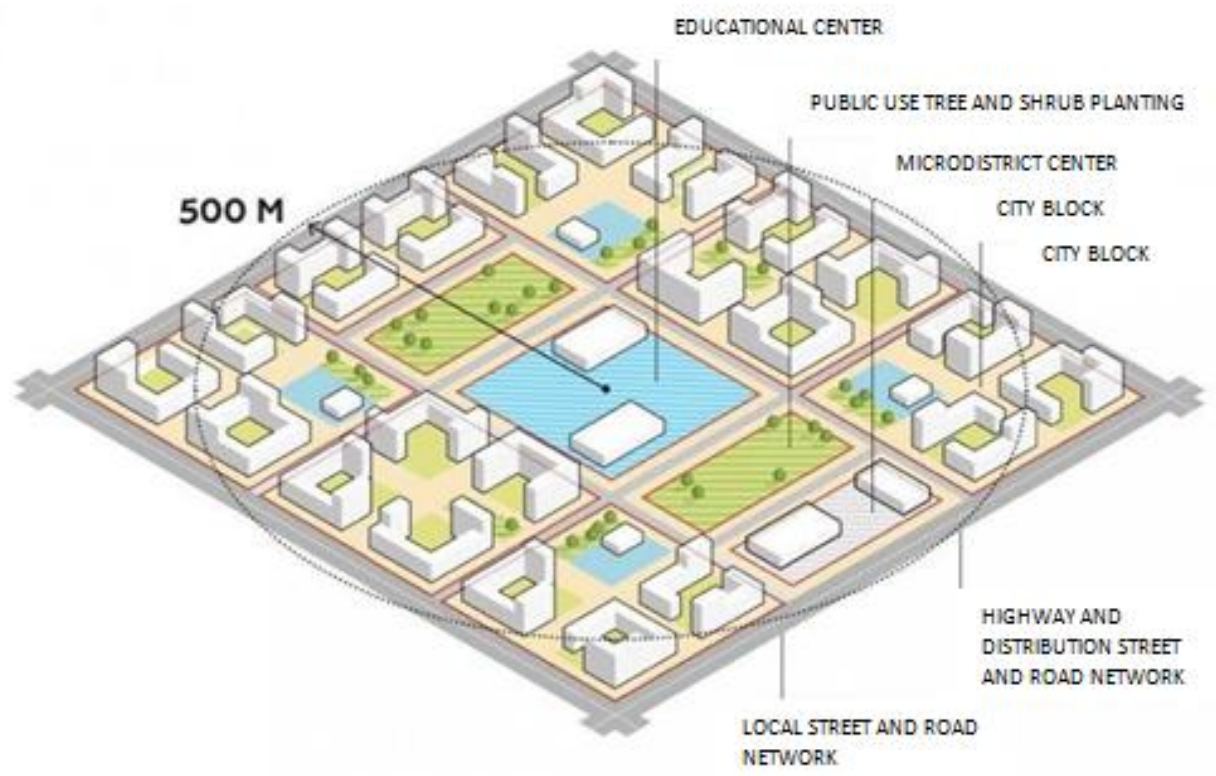

Fig. 3. Microdistrict.

It should be noted that development and effective functioning of facilities that are a part of the social infrastructure, their accessibility are essential conditions for improving the standard of living and quality of life of the country's population, contributing to the construction of a comfortable "compact city".

\section{Results}

As an example of the Blue Ocean strategy implementation for the purposes of enhancement of urban environment comfort, creation of a new infrastructure that will create conditions for the modernization of capital construction funds in the area of housing, it is possible to imagine development of microdistricts taking into account factors of the social infrastructure with the smart infrastructure, i.e. urban blocks with the smart infrastructure.

The value approach refers to the creation of value for the consumer. So, the research reveals the factor space oriented to the following indicators representing value for consumers (Fig. 4).

Characteristics of factor space indicators:

- General characteristics (F1) include the total area, the size of the living space, the size of the non-residential area, the size of the semi-recessed balcony and other balconies, views from the windows, the floor, on which the apartment under consideration is located, the height of the floor.

- Internal furnishing (F2) includes the finish, furniture, sanitary ware, built-in equipment, features of utilities.

- Utilities (F3) include the garbage collection system, the sewage system, gasification, cold water supply, hot water sully, heating, air conditioning, electricity, ventilation.

- Operational factors (F4) include organization of house management, provision of internal territory security. 


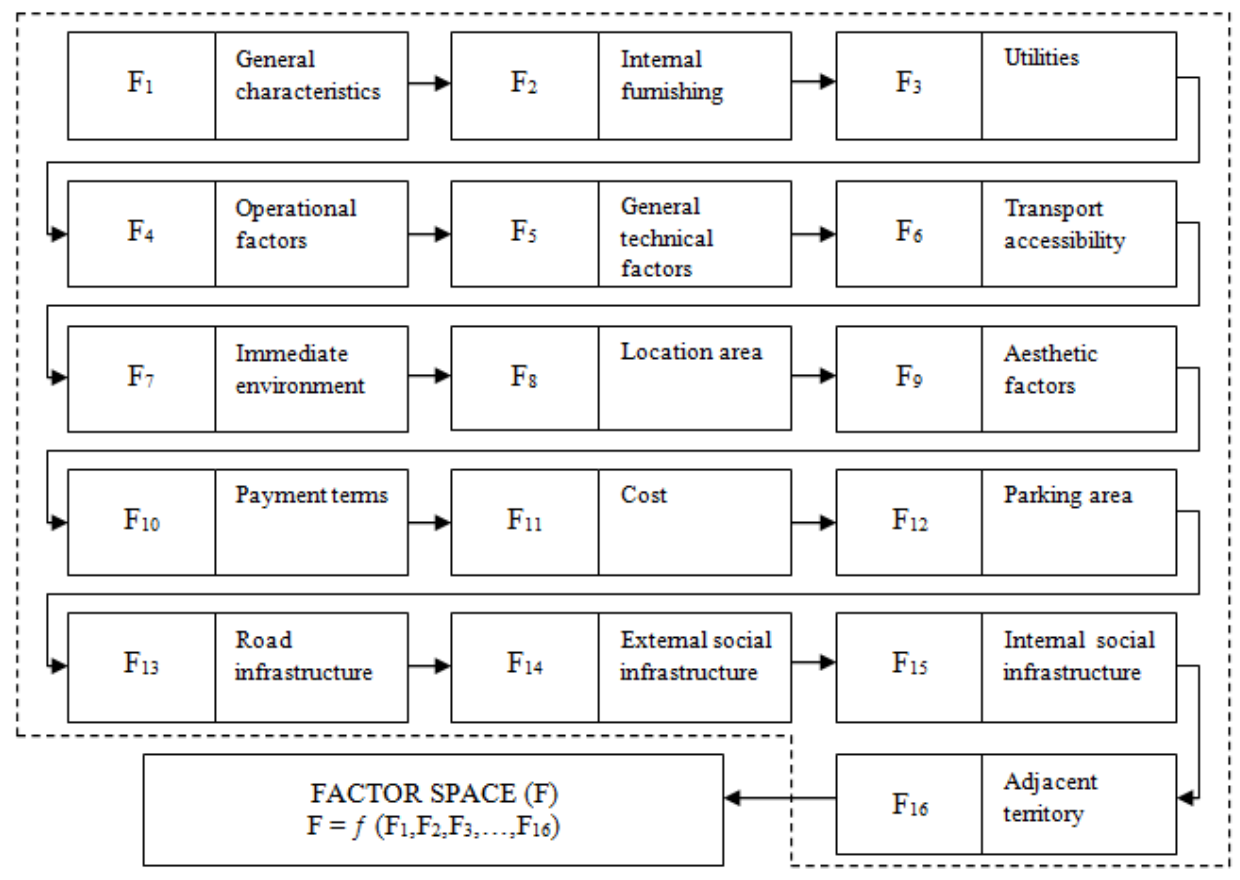

Fig. 4. Factor space (F).

- General technical factors (F5) include seismic activity, flood risks, climatic features, social equality and cultural harmony, crime-pronness of the area, lack of aggressive fields.

- Transport accessibility (F6) includes individual and group accessibility.

- The immediate environment (F7) includes proximity of parks, coastal and forest zones, presence of harmful enterprises, density of development/population.

- The location area (F8) includes seismic activity, flood risks, climatic features, social equality and cultural harmony, crime-pronness of the area, lack of aggressive fields.

- Aesthetic factors (F9) include altitude, facade design.

- Payment terms (F10) include the down payment, the monthly payment, the due date.

- The cost (F11) includes the cost of the apartment.

- The parking area (F12) includes heating, information about the structure (open/closed/underground), security.

- Road infrastructure (F13) includes bicycle paths, paving of pedestrian roads, asphalting of internal roads.

- External social infrastructure (F14) includes a set of facilities that create conditions for productive human activities in all spheres of life in the existing microdistrict, city.

- Internal social infrastructure (F15) includes a set of facilities that create conditions for productive human activities in all spheres of life within a built-up city block, microdistrict.

- The adjacent territory (F16) includes small architectural forms, the size of the territory adjacent to the building, perennial trees and shrubs, landscape design.

Factors that determine the quality and structure of smart infrastructure elements when building the microdistrict by urban blocks are identified for the factor space among all the factors in this research.

However, it should be noted that efficiency of building microdistricts with the use of smart infrastructure to obtain the most optimal result should be considered a "city - 
developer - consumers" trinity. As a result a three-factor model for the improvement of the efficiency of the investment and construction project implementation was created for this study.

For the city the smart infrastructure is presented as an element of increasing the attractiveness of the city, ensuring of the social function of real estate, comfortable living environment, contributing to the city's competitiveness.

For the developer - as an element, for which minimum efforts can be spent, the maximum possible result (profit) can be receibed, consider this project as promising and expedient and develop further on the real estate market.

For consumers - as another element considered when choosing a real estate item getting the maximum usefullnes and a possibility to choose the life environment. The area of residence in this case is important from the point of view of the value of smart infrastructure facilities, which ensures the competitiveness of both individual projects (facilities) and entire microdistricts and districts of the city.

We will create an economic-mathematical model to determine the effectiveness of the project and identify key objective functions in the economic-mathematical model that determine the efficiency of investment and construction project implementation (formula 1).

$$
\begin{gathered}
\text { Ef }=\mathrm{f}(\text { Ec, Env, B, C, S) }= \\
=\left\{\begin{array}{c}
\text { NPV } \rightarrow \text { max } \\
\text { IRR } \rightarrow \text { max } \\
\text { PI } \geq 1 \\
\text { PP } \rightarrow \text { min }
\end{array}+\left\{\begin{array}{c}
\text { Environmental efficiency (Env) } \rightarrow \text { max } \\
\text { Budgetary effeciency (B) } \rightarrow \text { max } \\
\text { Commercial efficinecy }(C) \rightarrow \text { max } \\
\text { Social efficiency (S) } \rightarrow \text { max }
\end{array}\right.\right.
\end{gathered}
$$

Where Ef is the efficiency of investment and construction project implementation taking into account the three-factor model consisting of the "city-developer-consumers" trinity.

Ec is economic efficiency, a presented set of such parameters as net present value $(\mathrm{NPV})$, internal rate of return (IRR), profitability index (PI), payback period (PP).

When calculating the efficiency, we modeled a project for the construction of an urban block with the smart infrastructure on the basis of the value concept. The data were compared with two projects, one of which was a project for the construction of conventional residential property without social infrastructure facilities and the second one - a project for the implementation of the classic version of the urban block (Table 1).

The project for the construction of an urban block with the smart infrastructure includes two 6-slab houses consisiting of different numbers of floors - from 15 to 24, a courtyard that includes a private area and a closed one. The first floor is intended for day-to-day service facilities, which include a grocery store, a household store, a pharmacy, a post office, a pizzeria, a beauty salon, a veterinary center, a laundry, mobile phone outlets, a flower shop, a bakery and a cafe.

Table 1. Efficiency of the implementation of projects for the construction of conventional residential property, urban blocks and urban blocks with the smart infrastructure.

\begin{tabular}{|l|c|c|c|}
\hline \multicolumn{1}{|c|}{ Efficiency indicators } & Urban block & $\begin{array}{c}\text { Urban block with } \\
\text { the smart } \\
\text { infrastructure }\end{array}$ & $\begin{array}{c}\text { Conventional } \\
\text { apartments }\end{array}$ \\
\hline \multicolumn{1}{c|}{$\mathbf{2}$} & $\mathbf{2}$ & $\mathbf{3}$ & $\mathbf{4}$ \\
\hline $\begin{array}{l}\text { Proceeds from project } \\
\text { implementation }\end{array}$ & $5,170,301,000.00$ & $5,219,387,000.00$ & $4,905,068,000.00$ \\
\hline $\begin{array}{l}\text { Costs plus unforeseen } \\
\text { expenses }\end{array}$ & $3,182,770,000.00$ & $3,294,934,000.00$ & $2,899,012,000.00$ \\
\hline Net Present Value & $6,002,400.00$ & $6,195,206.00$ & $5,373,600.00$ \\
\hline
\end{tabular}




\begin{tabular}{|l|c|c|c|}
\hline \multicolumn{1}{|c|}{ Efficiency indicators } & Urban block & $\begin{array}{c}\text { Urban block with } \\
\text { the smart } \\
\text { infrastructure }\end{array}$ & $\begin{array}{c}\text { Conventional } \\
\text { apartments }\end{array}$ \\
\hline \multicolumn{1}{|c|}{$\mathbf{1}$} & $\mathbf{2}$ & $\mathbf{3}$ & $\mathbf{4}$ \\
\hline (NPV) & $25.41 \%$ & $26.69 \%$ & $21.38 \%$ \\
\hline $\begin{array}{l}\text { Internal rate of return } \\
\text { (IRR) }\end{array}$ & 1.03 & 1.04 & 1.002 \\
\hline Profitability index (PI) & 52 & 50 & 65 \\
\hline $\begin{array}{l}\text { Payback period (PP), } \\
\text { months }\end{array}$ & 75 & 72 & 88 \\
\hline $\begin{array}{l}\text { Discounted payback } \\
\text { period (DPP), months }\end{array}$ & & & 68 \\
\hline
\end{tabular}

These forecast calculations show that the effectiveness of the implementation of the project for the construction of an urban block with the smart infrastructure is higher as compared to other facilities. On the basis of the calculations it can be concluded that the project for microdistrict development by urban blocks focused on the detailed elaboration of social infrastructure facilities is more viable and investment-attractive.

\section{Conclusions}

The project for the implementation of microdistricts within the framework of the value approach, which takes into account construction of urban blocks with the smart infrastructure, will help to solve two tasks simultaneously: to optimize costs for real estate sale at the expense of compact but comfortable apartments, and to ensure fulfillment of social obligations, which will generally promote development of a comfortable "compact city".

In general, focus on the three-factor model "city-developer-consumers" will help to increase the efficiency of the project. It is this combination that will improve the quality of urban and microdistricts development and satisfy needs of all participants in the investment and construction process.

\section{References}

1. Y. Kog, Practice Periodical on Structural Design and Construction (2018)

2. V. Kankhva, IOP Conference Series: Earth and Environmental Science, 90 (2017)

3. E. Nezhnikova, V. Kankhva, Izvestiya Vysshikh Uchebnykh Zavedenii, Seriya Teknologiya Tekstil'noi Promyshlennosti, 2(368) (2017)

4. B. Semaan, J. Hemsley, ISCRAM 2015 Conference Proceedings - 12th International Conference on Information Systems for Crisis Response and Management, 321-328 (2015)

5. I. Ptuhina, T. Spiridonova, T. Musorina, Applied Mechanics and Materials 725-726, 153-159 (2015)

6. O. Papelniuk, MATEC Web of Conferences 106, 08044 (2017)

7. E. Frolova, M. Vinichenko, A. Kirillov, O. Rogach, E. Kabanova, International Journal of Environmental and Science Education 11(15), 7421-7430 (2016)

8. I. Ptuhina, T. Spiridonova, T. Musorina, S. Kanyukova, A. Rezvaia, MATEC Web of Conferences 53, 01049 (2016) 
9. W. Chan Kim, R. Mauborgne, Blue Ocean Strategy (Harvard Business Review Press, 2015)

10. M. Porter, Competitive strategy, Techniques for Analyzing Industries and Competitors (The Free Press, 2011)

11. W.C. Kim, R. Mauborgne, Harvard business review, 1-7 (2015)

12. W.K. Hughen, D.C. Read. Land Use Policy 61, 1-11 (2017)

13. A.P.C. Chan, D.W.M. Chan, Y.H. Chiang, B.S. Tang, E.H.W. Chan, K.S.K. Ho, Journal of Construction Engineering and Management 130 (2), 188-198 (2004)

14. P.H. Brown, How Real Estate Developers Think: Design, Profits, and Community (University of Pennsylvania Press, 2015)

15. H. Osman, Structure and Infrastructure Engineering 12 (1), 108-121 (2016)

16. G. Seaden, M. Guolla, J. Doutriaux, J. Nash, Construction Management and Economics 21 (6), 603-612 (2003)

17. H. Donner, H.-S. Song, M. Wilhelmsson, Journal of Housing Economics 34, 60-68 (2016)

18. A.C. Kasim, M.M.G.M. Abdul Rahman, M. Mohd Raid, 25th International Business Information Management Association Conference - Innovation Vision 2020: From Regional Development Sustainability to Global Economic Growth, IBIMA, 3456-3465 (2015)

19. W.C. Kim, R. Mauborgne, Harvard business review 92 (5), 60-68 (2014)

20. A. Agnihotri, Journal of Strategic Marketing 24 (6), 519-528 (2016) 